\title{
Mesopelagic microbial carbon production correlates with diversity across different marine particle fractions
}

\author{
Chloé M. J. Baumas ${ }^{1} \cdot$ Frédéric A. C. Le Moigne $\mathbb{1}^{1} \cdot$ Marc Garel $^{1} \cdot$ Nagib Bhairy $^{1} \cdot$ Sophie Guasco ${ }^{1} \cdot$ Virginie Riou $^{1}$ •

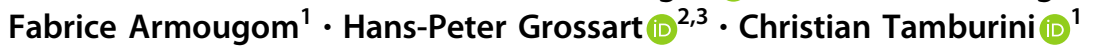

Received: 29 July 2020 / Revised: 2 December 2020 / Accepted: 9 December 2020 / Published online: 15 January 2021

(c) The Author(s) 2021. This article is published with open access

\begin{abstract}
The vertical flux of marine snow particles significantly reduces atmospheric carbon dioxide concentration. In the mesopelagic zone, a large proportion of the organic carbon carried by sinking particles dissipates thereby escaping long term sequestration. Particle associated prokaryotes are largely responsible for such organic carbon loss. However, links between this important ecosystem flux and ecological processes such as community development of prokaryotes on different particle fractions (sinking vs. non-sinking) are yet virtually unknown. This prevents accurate predictions of mesopelagic organic carbon loss in response to changing ocean dynamics. Using combined measurements of prokaryotic heterotrophic production rates and species richness in the North Atlantic, we reveal that carbon loss rates and associated microbial richness are drastically different with particle fractions. Our results demonstrate a strong negative correlation between prokaryotic carbon losses and species richness. Such a trend may be related to prokaryotes detaching from fast-sinking particles constantly enriching non-sinking associated communities in the mesopelagic zone. Existing global scale data suggest this negative correlation is a widespread feature of mesopelagic microbes.
\end{abstract}

\section{Introduction}

The oceanic biological carbon pump (BCP) is a complex set of mechanisms that regulates Earth's carbon (C) cycle by sequestrating part of the photosynthetically fixed carbon dioxide $\left(\mathrm{CO}_{2}\right)$ in the deep ocean $(>1000 \mathrm{~m})$ and the seafloor [1]. In essence, particulate organic carbon (POC) is

Supplementary information The online version of this article (https:// doi.org/10.1038/s41396-020-00880-z) contains supplementary material, which is available to authorized users.

Frédéric A. C. Le Moigne

frederic.lemoigne@mio.osupytheas.fr

$\checkmark$ Christian Tamburini

christian.tamburini@mio.osupytheas.fr

1 Aix-Marseille Université, Université de Toulon, CNRS, IRD, Mediterranean Institute of Oceanography (MIO, UM 110), Marseille, France

2 Department of Experimental Limnology, Leibniz Institute of Freshwater Ecology and Inland Fisheries, Stechlin, Germany

3 Institute of Biochemistry and Biology, Postdam University, 14469 Potsdam, Germany transported into the ocean's interior via gravitational sinking of marine particles $[2,3]$ of various types and sinking rates. The depth at which marine particles are remineralized in the ocean exerts a strong influence on the $\mathrm{CO}_{2}$ air/sea balance. The deeper this depth is, the more $\mathrm{CO}_{2}$ is stored over a long period of time, locked away from the atmosphere [4]. This $\mathrm{CO}_{2}$ sequestration is mostly vectored by gravitational sinking particles [2].

POC downward flux and sequestration (that is POC flux below $1000 \mathrm{~m}$ ) in the deep ocean is controlled by photosynthetic primary producers, but also by heterotrophic organisms transforming POC during its descent into the mesopelagic zone (euphotic zone base to $1000 \mathrm{~m}$ ). During their sinking, particles are grazed/repackaged into dense fecal pellets and/or fragmented into smaller particles by zooplankton [5] and abiotic processes [6]. Their organic carbon content is mainly remineralized by heterotrophic microorganisms [7, 8]. Hence, the POC flux is attenuated with depth through zooplankton activity and abiotic processes, but the final remineralization step (releasing dissolved $\mathrm{CO}_{2}$ ) is mainly performed by heterotrophic microorganisms $[9,10]$. However, currently no consensus exists either on the environmental drivers or the ecological processes that may dictate the activity of the heterotrophic 
prokaryotic community associated with fast-sinking particles at increasing depth. This prevents any adequate mechanistic representation of the activity, community network, or ecological lifestyle of particle-associated prokaryotes in oceanic food webs and biogeochemical models $[10,11]$.

Previoulsy, the majority of studies on prokaryotes attached to particles used conventional seawater bottle samplers followed by size fractionated filtration [12]. However, such samplers do not actively and quantitatively collect intact gravitational sinking particles [13, 14] and an adequate harvest of sinking particles remains a challenge [15]. Studies have also looked at the diversity of sinking particles collected using sediment traps [16], but did not relate prokaryotic production measurements nor estimates to it. Therefore, distinction between gravitational sinking particles vs. other particles (sinking or non-sinking fractions, see definition below), and their associated biogeochemical rates and/or ecological features has been rarely addressed.

For the first time, Turley and Mackie [17] used the Marine Snow Catcher (MSC [18]) to specifically sample different particle fractions to investigate in essence, fastsinking vs. non-sinking particles, and their attached prokaryotic cells concentration and activities. They found inconsistencies between the intrinsic carbon demand of the prokaryotic community and the corresponding carbon supply in the upper mesopelagic zone with prokaryotic heterotrophic production (PHP) being lower on fast-sinking particles relative to non-sinking ones. This is due to the scarcity of fast-sinking particles in oceanic waters. Later, Duret et al. [19] segregated particles using the MSC to study prokaryotic diversity associated with sinking vs. nonsinking particle fractions. Using $16 \mathrm{~S}$ rRNA gene sequencing, they revealed a strikingly different ecological behavior with $K$-strategists (specialists) prokaryotes thriving on the non-sinking fraction and $r$-strategists (generalists) being observed in high proportions on the sinking particles. This highlights important progresses in our mechanistic understanding of mesopelagic community dynamics on different particle fractions, but from a biogeochemical perspective, our understanding of the ecological drivers of $\mathrm{C}$ cycling within the mesopelagic is still limited.

Recently, a positive linear correlation was found between prokaryotic species richness and associated heterotrophic productivity in freshwaters [20]. Yet no study has related remineralization rates to the diversity of prokaryote communities in the ocean's interior. Such trait-based approaches are being increasingly used in marine ecology with plankton communities having lately received attention on a global scale [21], in particular primary producers [22]. However, the mesopelagic prokaryotic community and more specifically its particle associated fractions have received much less attention despite their known biogeochemical and climatic importance [23]. To date, concepts in ecological processes such as the relationships between secondary production and community diversity remain poorly studied.

Here, we provide the first assessment of remineralization rates of heterotrophic prokaryotes coupled to their diversity associated to the non-sinking and fast-sinking fractions at four depths horizons of the mesopelagic zone in the North Atlantic Ocean. Thereby, the "non-sinking fraction" comprises free-living prokaryotes and those attached to suspended particles, and the "fast-sinking fraction" refers to prokaryotes attached to fast-sinking particles (i.e., gravitational sinking particles) retrieved from the MSC. Measured PHP was used as an indicator of remineralization rates on fast-sinking and non-sinking prokaryotic fractions. Using $16 \mathrm{~S}$ rRNA sequencing, we identified key prokaryotic players and their potential ecological and metabolic functions to further predict prokaryotic processes involved in mesopelagic particle remineralization. In this study, we coupled cell-specific PHP rates (and further estimates of prokaryotic C loss rates) to prokaryotic species richness. Our results show that cell-specific rates vary little with depth on fast-sinking particles while they decrease strongly on non-sinking particles. Interestingly, microbial species richness decreases with depth for the fast-sinking particles while increases for non-sinking particles despite energetic resources being potentially available in fast-sinking particles. Finally, we found a strong negative relationship between cell-specific PHP rates and species richness. While the underlying mechanisms driving such a pattern are still unclear, our results suggest this negative correlation may be a widespread ecological trait of mesopelagic prokaryotic communities. This potentially increases $\mathrm{C}$ sequestration as the ability of the fast-sinking particle prokaryotic community to degrade organic $\mathrm{C}$ may not be as efficient as the ability of the more diverse community observed in the nonsinking fraction at any depths.

\section{Results and discussion}

\section{Fractions and associated prokaryotic heterotrophic production rates}

Using a marine snow catcher (MSC, see reference [18], Fig. S1), we collected and segregated the non-sinking (suspended particle attached prokaryotes and free-living prokaryotes, hereafter "non-sinking," obtained from the MSC's top part or Niskin bottles, see methods and supplementary material) and fast-sinking (i.e., gravitational sinking particles collected in the MSC's plate, see methods and supplementary material) prokaryotic fractions. Samples were taken at $28,70,128$, and $500 \mathrm{~m}$ depth at the Porcupine 
a

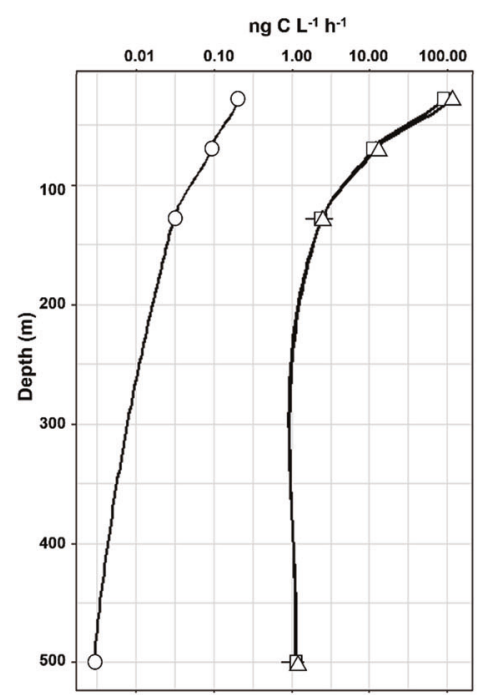

b

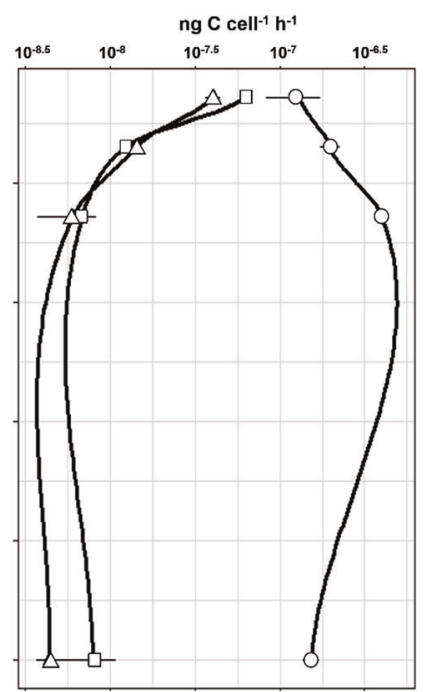

c

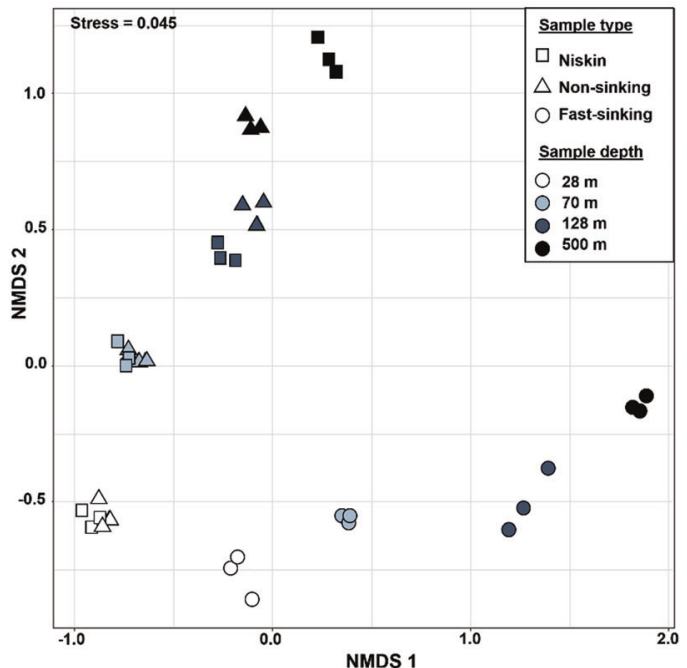

Fig. 1 Prokaryotic heterotrophic production and OTUs dissimilarity in the three different fractions. Depth profiles of total (a) and cellspecific (b) prokaryotic heterotrophic production (PHP) in three different fractions (see main text): (i) seawater sampled with Niskin bottles and (ii) non-sinking and (iii) fast-sinking prokaryotic fractions sampled using a marine snow catcher (MSC) at the PAP site during the DY032 cruise. c Non-metric multi-dimensional scaling (NMDS) ordination plot (Bray Curtis distance) showing the dissimilarity of operational taxonomic unit (OTUs) between the different sample types at 28, 70, 128, and $500 \mathrm{~m}$. The stress value of the NMDS analysis is 0.045 .
Abyssal Plain site (PAP site), a longstanding deep observation station in the North Atlantic [24] (see methods for a brief description of basic biogeochemical settings at this location). These depths correspond to MSCs deployed at 10 $\mathrm{m}, 50 \mathrm{~m}$ and $110 \mathrm{~m}$ below the base of the mixed layer depth (MLD), i.e., MLD $+10 \mathrm{~m}, \mathrm{MLD}+50 \mathrm{~m}$, MLD $+110 \mathrm{~m}$, respectively (see reference [25] for details). Conventional bottle samplers (NISKIN bottles) were also used for a direct comparison (see methods for detailed explanation).

On site, vertical profiles of temperature, light (as percentage of photosynthetically available radiation, PAR) and chlorophyll concentrations corresponding to the four MSC deployments were consistent (Fig. S2). Temperature ranged from $15^{\circ} \mathrm{C}$ in surface to $12^{\circ} \mathrm{C}$ below $100 \mathrm{~m}$ depth. Chlorophyll concentrations ranged from 0.5 to $1.7 \mathrm{mg} \mathrm{m}^{-3}$ in surface waters and sharply decreased below $50 \mathrm{~m}$ depth (Fig. S2). The dominant component of fast-sinking particles were phytodetrital aggregates (96\% of sinking POC at $36 \mathrm{~m}$, increasing to $66 \%$ at $500 \mathrm{~m} \mathrm{[25]).} \mathrm{The} \mathrm{proportion} \mathrm{of} \mathrm{zoo-}$ plankton fecal pellets added to unidentified phytodetritus increased with depth but remained below $40 \%$ at $500 \mathrm{~m}$ [25].

From 28 to $500 \mathrm{~m}$ depth, prokaryotic heterotrophic production rates (PHP, i.e., quantification of ${ }^{3} \mathrm{H}$-Leucine uptake by heterotrophic prokaryotes for biomass production) on the nonsinking fraction decreased from 111.755 to $1.161 \mathrm{ng} \mathrm{C} \mathrm{L}^{-1} \mathrm{~h}^{-1}$ (Fig. 1a and Table S1). PHP rates on fast-sinking particles decreased by two orders of magnitude, from 0.211 to $0.003 \mathrm{ng}$ $\mathrm{C} \mathrm{L} \mathrm{L}^{-1} \mathrm{~h}^{-1}$ between 28 and $500 \mathrm{~m}$ depth when reported to the volume sampled (see methods and supplementary material for details). Normalizing these rates to the number of prokaryotic cells, cell-specific PHP rates (see methods and supplementary material for details) on the non-sinking fraction decreased from $4.1 \times 10^{-8}$ to $4.4 \times 10^{-9} \mathrm{ng} \mathrm{C}$ cell ${ }^{-1} \mathrm{~h}^{-1}$ between 28 and $500 \mathrm{~m}$ depth (Fig. 1b and Table S1), similarly to those obtained previously $[17,26]$. In contrast, cell-specific PHP rates on fastsinking particles varied little with depth (from $1.29 \times 10^{-7} \mathrm{ng} \mathrm{C}$ cell $^{-1} \mathrm{~h}^{-1}$ at $28 \mathrm{~m}$ to $1.53 \times 10^{-7} \mathrm{ng} \mathrm{C}$ cell $^{-1} \mathrm{~h}^{-1}$ at $500 \mathrm{~m}$ with a maximum of $4.00 \times 10^{-7} \mathrm{ng} \mathrm{C}$ cell $^{-1} \mathrm{~h}^{-1}$ at $128 \mathrm{~m}$, Fig. 1b). At each sampling depth, cell-specific PHP rates on fast-sinking particles were higher than of the non-sinking fraction (Fig. 1b, Table S1).

Using $16 \mathrm{~S}$ rRNA sequences (16 S rRNA are reverse transcripted to cDNA targeting viable prokaryotes), we further assessed dissimilarities (based on the Bray-Curtis dissimilarity index, see further explanation in the methods section) between the different prokaryotic fractions considered. We generated a non-parametric multidimensional scaling (NMDS) ordination based on Bray-Curtis distance of Operational Taxonomic Units (OTUs) distribution in the different fractions (Fig. 1c). Similar to PHP rates, this revealed a clear dichotomy between prokaryotic communities attached to fast-sinking particles (NMDS1) and those belonging to the non-sinking fraction (NMDS2). In addition, dissimilarities between both prokaryotic communities (non-sinking and fast-sinking fractions) increased with depth (Fig. 1c). 
Our results suggest that prokaryotic diversity and activity (i.e., PHP) differed in two different, but consistent, manners depending on the type of the prokaryotic fraction (Figs. 1 and 2). In addition, given the similarities in activity and diversity between Niskin and MSC's top samples (both non-sinking and free-living prokaryotes), hereafter non-sinking fraction (see Supplementary Material), we assume that further distinction between Niskin and MSC's top samples is no longer necessary. This is consistent with previous work showing that bottle samplers avoid fast-sinking particles by design [13, 15] and do not represent bulk activity or diversity as generally assumed [12].

\section{Diversity of different prokaryotic fractions}

The 16S rRNA sequences enabled examination of viable prokaryotic species richness associated with both fast- and non-sinking prokaryotic fractions. The observed species richness (see methods and supplementary material) of prokaryotic communities attached to fast-sinking particles decreased drastically (from 314 to 128) between 28 and $500 \mathrm{~m}$ depth. Conversely, species richness increased from 262 to 531 for the non-sinking fraction between 28 and $500 \mathrm{~m}$ (Fig. S3 and methods). A similar depth-related increase in species richness of the prokaryotic community of non-sinking prokaryotic fractions has been reported previously for the Atlantic Ocean [27, 28].
The relative abundances of the twenty most represented, active families across all samples are shown in Fig. 2. Results revealed a clear divergence of prokaryotic communities between fast-sinking vs. non-sinking prokaryotic fractions as a function of depth. At $28 \mathrm{~m}$ depth, the proportions of the twenty most represented families were relatively similar in both fractions; only their relative abundances differed. The non-sinking prokaryotic community was mainly dominated by Rhodobacteraceae and SAR11 Clade 1 (10\% of the relative abundance each) as well as Flavobacteriaceae (6\%), and the prokaryotic community attached to fast-sinking particles was dominated by Flavobacteriaceae, Rhodobacteraceae, Saprospiraceae and the SAR11 Clade 1 (13, 9, 5, 4\% respectively) (Fig. 2).

At $70 \mathrm{~m}$ depth (upper mesopelagic zone [25]), the nonsinking prokaryotic communities changed towards a higher proportion of Nitrosopumilaceae and lower proportions of the SAR11 Clade 1, Rhodobacteraceae and Flavobacteriaceae $(9,9,6,3 \%$ respectively) relative to $28 \mathrm{~m}$. On the fast-sinking particles however, Flavobacteriaceae represented $10 \%$ while Moraxellaceae increased to $11 \%$. The relative abundance of Rhodobacteraceae at $70 \mathrm{~m}$ depth decreased more in the fast-sinking than in the non-sinking prokaryotic fraction (3 and $6 \%$ respectively). In addition, our results highlight the presence of copiotrophs in the fastsinking fraction (i.e., Flavobacteraceae and Saprospiraceae). At $128 \mathrm{~m}$, we observed higher proportions of Nitrosopumilaceae and lower proportions of SAR11 Clade 1
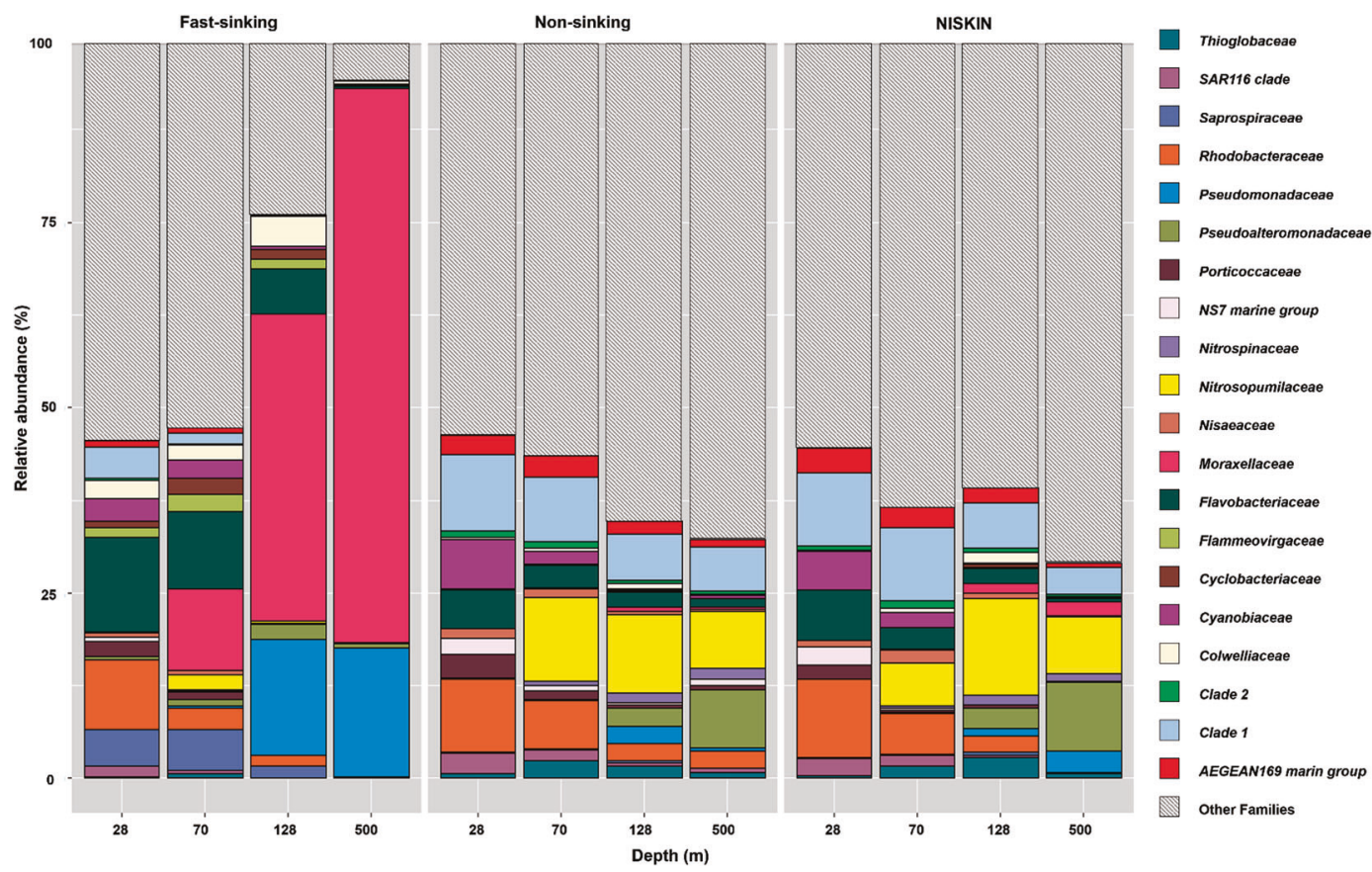

Fig. 2 Relative abundance of prokaryotic groups (family level). Three different types of samples were distinguished: (i) seawater sampled with Niskin bottles, (ii) non-sinking and (iii) fast-sinking prokaryotic fractions sampled with a marine snow catcher (MSC) at

the PAP site during the DY032 cruise at 28, 70, 128, and $500 \mathrm{~m}$ depth. Only the 20 most abundant families are shown, others family proportions are merged into the hatched part. 


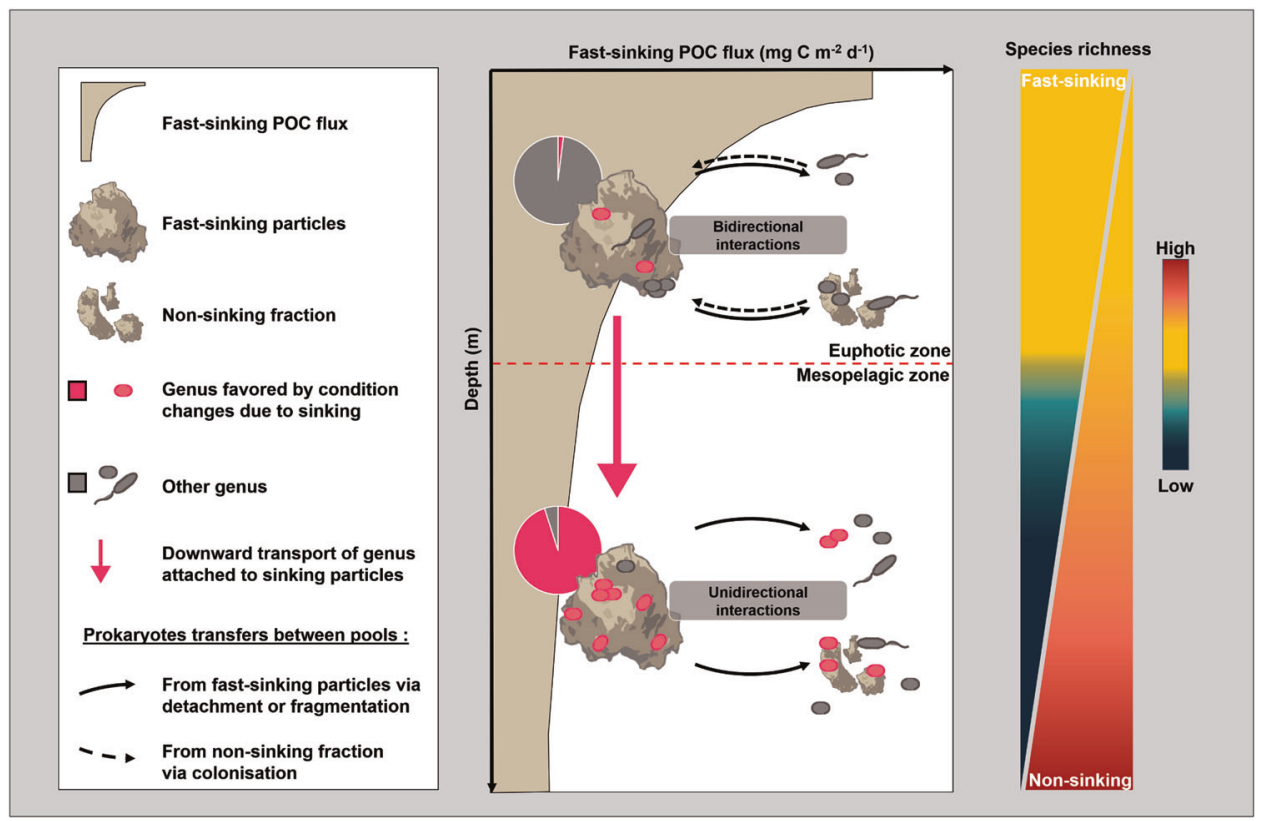

Fig. 3 Conceptual diagram illustrating the different interactions between prokaryotic communities associated with fast-sinking and non-sinking fractions. In the euphotic zone, multiple interactions occur in both directions during the initial formation of particles. Dense particles rapidly sink out of the euphotic zone into the mesopelagic zone. The downward transfer of fast-sinking particles is attenuated due to prokaryotic production, but also transports particle-attached prokaryotes from the surface to depth. Changes in environmental

(12 and 6\%, respectively) in the non-sinking fraction. In this fraction, the relative abundance of Rhodobacteraceae was low (2\%), yet Pseudoalteromonadaceae (marginal at 28 and $70 \mathrm{~m},<0.1 \%$ ), increased to $3 \%$ of the total relative abundance at $128 \mathrm{~m}$. At $500 \mathrm{~m}$, Pseudoalteromonadaceae along with Nitrosopumilaceae dominated the non-sinking fraction ( 9 and $8 \%$, respectively). Note that over $50 \%$ of the nonsinking prokaryotic community consists of low-abundant families (labeled as other families in Fig. 2, <1\%). This proportion increased with depth along with an increase of species richness (Fig. S3). Such increase in species richness may indicate that resources are shared between prokaryotes of different origins [29]. In contrast, the fast-sinking prokaryotic communities showed a radically different pattern at depth (Fig. 2). Interestingly, the proportion of Moraxellaceae and Pseudomonadaceae increased between $128 \mathrm{~m}$ (41 and 16\%, respectively) and $500 \mathrm{~m}$ (75 and 17\%, respectively). This dominance resulted in a drastic decline in species richness of the fast-sinking prokaryotic community with depth (Fig. S3). At $500 \mathrm{~m}$ depth, $92 \%$ of the total community was represented by only two bacterial genera, namely Acinetobacter (Moraxellaceae) and Pseudomonas (Pseudomonadaceae), mostly represented by two OTUs each. Among these four OTUs, we assigned with no ambiguity only one OTU with $100 \%$ of sequence identity conditions induced by sinking (e.g., pressure, temperature, variation in downward flux and substrate quality) result in a drastic decrease in particle-attached species richness favoring certain prokaryotic genera. Further fragmentation of fast-sinking particles into non-sinking particles and cell detachment from particles enriches the surrounding nonsinking prokaryotic communities with these genera. The fast sinking POC flux is plotted after reference [25].

and coverage with Acinetobacter albensis ANC 4874 (described by reference [30]). Previous studies found Acinetobacter and Pseudomonas in water samples collected using Niskin bottles [31, 32], but also on particles collected using sediment traps [33]. Acinetobacter is one of the most frequently bacterial lineage retrieved from deep subsurface sediments and Pseudomonas genera were previously isolated from deep sediments [34]. The above studies do not correspond to fast-sinking particles only, but this notion suggests that the presence of both Acinetobacter and Pseudomonas genera associated with marine particles is not unusual.

Differences between fast- and non-sinking prokaryotic communities greatly increased in the mesopelagic zone relative to those in the euphotic zone (Figs. 1 and 2). Between 28 and $500 \mathrm{~m}$ depth, environmental conditions drastically differ in terms of light, temperature, and pressure (Fig. S2). Moreover, the quantity [25], and most likely the quality, of available organic carbon [35, 36] also differed for each of the prokaryotic fractions. Organic matter availability was presumably higher on fast-sinking particles as indicated by the presence of copiotrophs. Shifts towards a more diverse non-sinking prokaryotic community with depth were already reported by others $[12,37,38]$ and the high prokaryotic species richness 
observed on non-sinking particles (Fig. S3), whether abundant or scarce, suggests a higher functional potential. This may indicate a higher degree of adaptation of nonsinking relative to fast-sinking porkaryotic communities via mechanisms such as competition and resistance to nutrient scarcity and pressure when changes in environmental conditions occur more slowly [39].

Clear differences in observed PHP rates and community level diversity between both fast- and non-sinking prokaryotic communities raise fundamental questions about the connectivity and dynamics shaping prokaryotic communities in the mesopelagic zone. Previous experimental and theoretical studies demonstrated that plumes of dissolved organic matter forming in the wake of sinking particles do attract free-living, chemotactic prokaryotes [8, 40]. Generally, this is assumed to be the main pathway of sinking particle colonization [41]. In the following section, we challenge this view.

\section{Dynamics between fast-sinking and non-sinking prokaryotic communities}

In the euphotic zone ( $28 \mathrm{~m}$ here), non- and fast-sinking prokaryotic communities share ca. 53\% of all OTUs (Fig. S4). In this layer, the combination of biotic and abiotic processes represents a highly interconnected network involving prokaryotic activities, zooplankton feeding and turbulent mixing $[9,19,42]$. As a result, the connectivity between prokaryotic communities associated to the non- and fast-sinking fractions is likely high. Prokaryotes could opt for an attached lifestyle either by active particle colonization (free-living fraction) or by thriving on source particles already before subsequent aggregation to larger particles. This assumption is confirmed by the frequent co-occurrence of most families in the fast- and non-sinking prokaryotic fractions (Fig. 2, $28 \mathrm{~m}$ depth). For instance, Rhodobacteraceae and Flavobacteraceae are known as primary colonizers of particles in the euphotic zone [43].

In the mesopelagic zone, drastic changes in community composition and activities occurred among the different prokaryotic fractions (Figs. 1 and 2). From a total of 1013 OTUs, only $16 \%$ were still shared by both fast- and non-sinking fractions at $500 \mathrm{~m}$ depth (Fig. S4, Table S2). Prokaryotic diversity increased with depth for the nonsinking prokaryotic fraction, but drastically decreased on fast-sinking particles with sequences belonging almost exclusively to two genera, i.e., Acinetobacter and Pseudomonas (Figs. 2 and 3). Both genera are important for the degradation of organic matter in natural environments [44, 45]. For instance, Pseudomonas' genome is one of the largest in the bacterial world with a battery of genes enabling them to withstand various stresses [46]. Although competitiveness of Acinetobacter and Pseudomonas in highly diverse microbial communities is deemed low, they can rapidly adapt to drastic environmental changes in pressure, substrate composition or temperature [44-48]. Consequently, the constant increase in their relative abundance with depth (Fig. 2) could indicate an enhanced selective advantage caused by rapid changes in environmental conditions and substrate composition.

To illustrate this, we estimated growth rates of the total heterotrophic prokaryotic community of cells attached to sinking particles using cell-specific heterotrophic production rates and assuming a conservative conversion factor of $12 \mathrm{fg} \mathrm{C}$ cell $^{-1}$ (see "methods" section). These estimates show that the fast-sinking attached heterotrophic prokaryotic community not only persist but is actively growing, varying little with depth from 0.13 to $0.15 \mathrm{~h}^{-1}$ at 28 and $500 \mathrm{~m}$ depth, respectively, with a maximum growth rate of $0.4 \mathrm{~h}^{-1}$ at 128 $\mathrm{m}$. The growth rates of the total heterotrophic prokaryotic community attached to fast-sinking particles are at least one order of magnitude higher than those of the non-sinking fraction. In parallel, while the specific diversity is decreasing on fast-sinking particles, we observed an increase of the relative proportion of two genera with depth (Acinetobacter and Pseudomonas comprised 57 and $92 \%$ of the prokaryotic community at $128 \mathrm{~m}$ and $500 \mathrm{~m}$ respectively). This, together with the fact that the growth rates of the total heterotrophic prokaryotic community vary little with depth, we propose that the development of both Acinetobacter and Pseudomonas may explain the observed constancy in the total community growth rates while non-adapted taxa to environmental changes became inactive or disappeared. Interesting enough, testing the effects of hydrostatic pressure and temperature on growth of a piezotolerant Pseudomonas experimentally, Kaneko et al. [47] show a constant growth rate until $1000 \mathrm{~m}$ depth and a decreasing growth rate from $2000 \mathrm{~m}$ depth simulated.

The frequent occurrence of Acinetobacter species in deep subsurface sediments [34] together with their capability to produce biofilms and pili as well as their lack of motility and chemotaxis [44] indicate a potential specialization for an attached life style, e.g., on fast-sinking particles. Our results show that Acinetobacter and Pseudomonas species indeed contribute to 4 and $2 \%$, respectively, of the non-sinking prokaryotic communities at $500 \mathrm{~m}$. Thus, we believe that there is active growth resulting in an active release of prokaryotes rather than an active colonization from the surrounding water during particle sinking. While both, active release of prokaryotes to the surrounding water and active colonization from the surrounding water can occur simultaneously, in this case, we believe that active release of prokaryotes dominates. This is mainly because we observed a clear decrease in prokaryotic diversity on the fast-sinking particles fraction (Fig. 3). If a frequent prokaryotic colonization from non-sinking to fast-sinking fractions would occur at depth, prokaryotic diversity 


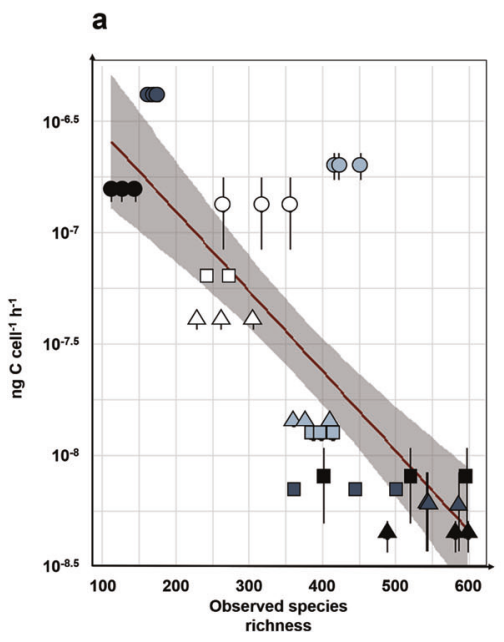

Fig. 4 Relationships between species richness and prokaryotic heterotrophic production. Observed species richness (see methods) and cell-specific prokaryotic heterotrophic production (PHP) rates in C units in three different fractions: (i) seawater sampled with Niskin bottles, (ii) non-sinking and (iii) fast-sinking prokaryotic fractions sampled with a marine snow catcher (MSC) at 4 water depths $(28,70$, 128 , and $500 \mathrm{~m}$ ). Errors bars represent the standard deviation of PHP

should also increase in the fast-sinking fraction with depth (i.e., mimicking the increase in diversity observed in the non-sinking fraction). This is not the case (Figs. 3 and S3). Also, the core microbiome (OTUs shared among all fractions, Fig. S4) between fractions decreases by $65 \%$ between 70 and $500 \mathrm{~m}$. In addition, the four Acinetobacter and Pseudomonas OTUs of interest (virtually absent in the nonsinking fraction at 28 and $70 \mathrm{~m}$ depth) show potential traits of a particle attached lifestyle [44, 49].

The consistent increase of Acinetobacter OTUs (all nonmotile [50]) in the non-sinking fraction with depth indicates a certain degree of constant prokaryotic detachment from fastsinking particles. In surface waters, the four Acinetobacter and Pseudomonas OTUs of interest are present in relatively limited abundance in the fast-sinking fraction and absent in the non-sinking fraction (Fig. 2). Nonetheless, on the fastsinking fraction, their relative abundance greatly increased with depth, simultaneously appearing in the non-sinking fraction but in relatively limited abundance. The fact that these four OTUs started appearing in the non-sinking fraction at $128 \mathrm{~m}$ suggests that sinking particles may act as vertical vectors increasing the prokaryotic diversity in the ambient water at greater depth. Furthermore, our results indicate that taxa poorly represented in the euphotic zone can be positively selected by a strong environmental selective pressure on fastsinking particles during their rapid descent. This seems to enrich deep waters, and presumably the seafloor, with particle-specific prokaryotes (Fig. 3).

We show that the high prokaryotic diversity in the nonsinking fraction at depth (Figs. 2 and S3) includes multiple b

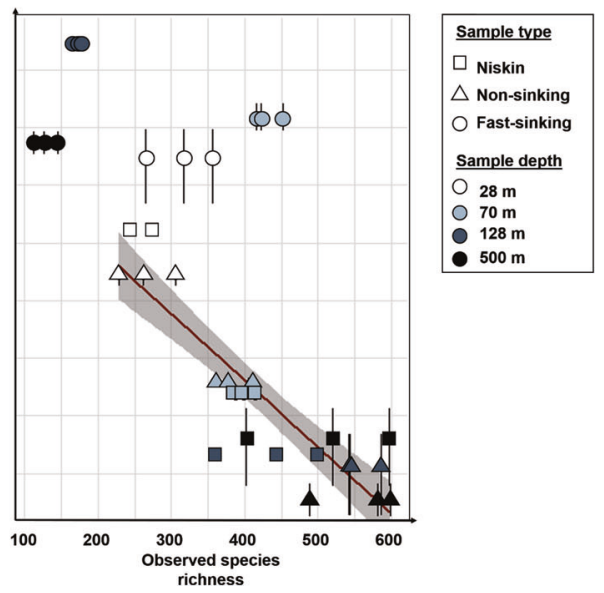

rates. Equations of both correlations are provided, see main text for more information. a Linear regression including all points (cell-specific PHP $=-6.19-0.00359 \times$ Obs, $r^{2}=0.59, P=3.9 \times 10^{-8}, n=$ 36), (b) with points corresponding to fast-sinking particles excluded from the regression (cell-specific PHP $=-6.88-0.00289 \times$ Obs, $r^{2}=$ $\left.0.80, P=4.3 \times 10^{-9}, n=24\right)$.

taxa with potential capabilities for motility and chemotaxis. Such capacities may allow non-sinking prokaryotes to sense and track loci of high nutrient concentrations, e.g., within plumes of organic matter behind fast-sinking particles [26, 41]. Using Niskin bottles sampling, previous study [51] detected a suite of motility and adhesion genes in SAR324 clade cells. However, in the mesopelagic zone we observed that SAR324 clade members were basically absent from the fast-sinking particles but contributed between 4 and $7 \%$ of the relative abundance of the non-sinking prokaryotic fraction at the order level. This notion suggests that they may attach to non-sinking rather than to fast-sinking particles as has been previously assumed [41]. This suggestion is also confirmed by other prokaryotic taxa, which do not show any evidence of active colonization of fast-sinking particles from the nonsinking prokaryotic communities in the mesopelagic zone (Fig. 2). Consequently, our results suggest mainly an unidirectional transfer of prokaryotes from fast-sinking to the non-sinking fraction in the mesopelagic zone (Fig. 3). The differences between the particle-associated communities appeared to be due to internal changes in the attached microbial community rather than de novo colonization during the sinking of particles as shown previously [52].

\section{Prokaryotic diversity to heterotrophic production relationships}

Multiple studies have investigated the relationship between species richness and climate relevant ecosystem functions provided by the ocean [53]. The vast majority of studies, 
however, examined phytoplankton primary producers [54]. To our knowledge, combined measurements of oceanic prokaryotic secondary production (i.e., PHP) and species richness related to different prokaryotic fractions have never been done before.

We found a strong negative linear correlation between cell-specific PHP rates and observed species richness (see methods and supplementary text) (cell-specific PHP = $-6.19-0.00359 \times$ Obs, $r^{2}=0.59, P=3.9 \times 10^{-8}, n=36$; Fig. 4a). When excluding the fast-sinking fraction, the significance of this relationship increased (cell-specific PHP $=-6.88-0.00289 \times$ Obs, $r^{2}=0.80, P=4.3 \times 10^{-9}$, $n=24$; Fig. $4 \mathrm{~b}$ ). This highlights the fact that particle fractions, dynamics and prokaryotic lifestyle represent important drivers for mesopelagic POC remineralization.

PHP, however, represents only part of the overall prokaryotic C loss (e.g., remineralization). Yet, it is possible that prokaryotic $\mathrm{C}$ losses can be estimated using a specific value of prokaryotic growth efficiency [55] (i.e., the amount of new bacterial biomass produced per unit of organic $\mathrm{C}$ substrate assimilated). To convert PHP rates into C remineralization rates, we used a prokaryotic growth efficiency of $8 \%$ [9] for the non-sinking fraction and a respiratory coefficient of 1 based on respiration measurements by [25] for the fast-sinking fraction (see Table S1 and supplementary text for explanation). This conversion provides confidence that the negative trend between cell-specific PHP rates and species richness (Fig. 4) also holds true for mesopelagic organic $\mathrm{C}$ remineralization rates and species richness.

Positive linear relationships between species richness and primary production have been frequently observed in various ecosystems [53, 54]. They can be explained by two theories, whereby an increasing species number initially present in a system could (1) enhance the encounter probability of exceptionally productive species ("selection probability effect" theory) and/or (2) result in more mixed communities of prokaryotic species with more contrasting ecological functions enabling them to use the limiting resources more efficiently and thus reducing interspecies competition ("complementary effect" theory) [56]. Most of these studies focus exclusively on the effects of biodiversity on primary production [57] patterns with little focus on the ocean. In a shallow freshwater estuarine lake, a recent similar study has been performed, but only with surface samples [20]. It revealed a positive linear relationship between prokaryotic species richness and secondary production. In contrast to our study, Schmidt et al. [20] took seasonal variations into account and only distinguished between free-living and particle-attached prokaryotic fractions. Most importantly, no depth-related effects were addressed, which may explain the opposite relationship from the one we have unveiled.
The negative relationship between prokaryotic species richness and secondary production in our study seems to be mainly driven by the non-sinking prokaryotic fraction, which shows a relatively high species richness in combination with low cell-specific PHP rates. In contrast, fastsinking particles possess relatively low prokaryotic species richness in combination with high cell-specific PHP rates (Fig. 4a). Consequently, high species richness does not necessarily result in high secondary production rates. This relationship is fundamentally different to what is currently accepted for phytoplankton and prokaryotic communities [22]. Yet, the underlying mechanisms driving this trend (Fig. 4) remain largely unknown.

In the mesopelagic ocean, fast- and non-sinking organic matter exhibits a diverse pool of organic substrates [58]. This may increase functional and phylogenetic diversity of prokaryotic communities with increasing depths relative to those in surface waters [59]. In addition, mesopelagic freeliving and non-sinking attached prokaryotic communities experience prolonged water-mass residence times [60], which allow for more stable environmental conditions and hence prokaryotic niche separation. We propose that dynamics of mesopelagic fast-sinking particles (high sinking velocities, $>27 \mathrm{~m} \mathrm{~d}^{-1}$, see "methods" and reference [25]) in combination with rapid changes in environmental conditions favor "local endemism" (Fig. 2) of the associated prokaryotic communities to gravitational fast-sinking particles. Furthermore, fragmentation of fast-sinking into nonsinking particles and active detachment of cells may potentially enrich the surrounding non-sinking prokaryotic fractions increasing their overall species richness (Fig. 3). This may explain the observed negative relationship between species richness and cell-specific biomass production in the non-sinking prokaryotic fraction.

\section{Linking community diversity to mesopelagic ocean ecosystem services}

Overall, our results suggest that trends between prokaryotic species richness and function are not straightforward and require an adequate assessment before any generalizations can be made. Given the intrinsic differences between prokaryotic lifestyles, additional distinguishing features between fast- and non-sinking prokaryotic fractions seem inevitable. Future efforts to gain a mechanistic understanding of the two main ecosystem functions in the mesopelagic zone [23], i.e., $\mathrm{CO}_{2}$ sequestration via mainly fast-sinking particles [23] and mesopelagic $\mathrm{C}$ consumption via mainly the non-sinking prokaryotic fraction [9] need to take into account these fundamental differences in prokaryotic lifestyle. For better generalization, we compiled a global range of species richness and PHP rates data (available in the literature, but not necessarily measured 
Table 1 Species richness and measured cell-specific prokaryotic heterotrophic production rates at various locations.

\begin{tabular}{llllll}
\hline & Depth & Species richness & PHP $\left(\right.$ ng C cell $\left.{ }^{-1} \mathrm{~h}^{-1}\right)$ & References species richness & References PHP \\
\hline Atlantic & Euphotic & $20-85$ & $5.81 \times 10^{-10}-6.90 \times 10^{-06}$ & {$[27,37]$} & {$[27,37]$} \\
& Mesopelagic & $40-150$ & $4.52 \times 10^{-11}-3.4 \times 10^{-07}$ & {$[27,37]$} & {$[27,37]$} \\
Pacific & Euphotic & $451-1254$ & $1.77 \times 10^{-08}-2.08 \times 10^{-08}$ & {$[79-81]$} & {$[82]$} \\
& Mesopelagic & $346-1748$ & $2.78 \times 10^{-08}-3.75 \times 10^{-08}$ & {$[79-81]$} & {$[82]$} \\
Indian & Euphotic & $46-47$ & $2.4 \times 10^{-08}-3.00 \times 10^{-07}$ & {$[83]$} & {$[84,85]$} \\
& Mesopelagic & $56-56$ & $1.8 \times 10^{-09}-1.00 \times 10^{-07}$ & {$[83]$} & {$[84,85]$} \\
Indian/Atlantic/Pacific & Euphotic & $240-1100$ & $5.48 \times 10^{-08}-1.67 \times 10^{-07}$ & {$[12]$} & {$[12]$} \\
& Mesopelagic & $250-1000$ & $4.17 \times 10^{-08}-1.67 \times 10^{-07}$ & {$[12]$} & {$[12]$} \\
\hline
\end{tabular}

simultaneously) across the Atlantic, Pacific and Indian Oceans (Table 1). While this compilation is not exhaustive, species richness seems to consistently increase with depth (from the euphotic to the mesopelagic zone). Similarly, cellspecific PHP rates systematically decrease with depth. Although all observations reported in Table 1 mainly look at the non-sinking fraction, depth-related trends are consistent with our results. This suggests that the trends we observed in the North Atlantic at the PAP site (Fig. 4) may be widespread throughout the ocean and reflect genuine ecological traits of mesopelagic microbes.

Genomic sequencing approaches are used [21] increasingly enabling large scale screening of marine prokaryotic and eukaryotic (both auto- and heterotrophic) species richness. In parallel, trait-based models [61] are developed with the intention to include genomic information in conventional biogeochemical models [62]. The links between climate relevant ocean ecosystem functions such as primary production or BCP related fluxes and various ecological traits (e.g., biodiversity or size $[21,54,63]$ ) are often poorly constrained and occasionally display significant mismatches [64]. Studies on species richness-function relationships are keys to a better mechanistic understanding, required urgently for future projections of major ocean-climate feedback mechanisms.

Furthermore, large scale assessment of mesopelagic prokaryotic communities [22] and their associated metabolic functions are necessary to elucidate the importance of mesopelagic prokaryotic communities for oceanic $\mathrm{CO}_{2}$ sequestration [9]. Assuming that functionality changes in accordance to diversity, our study shows a direct relationship between prokaryotic species richness and potential functionality, which seem to be controlled by the rate of changes in environmental conditions during particle sinking. This unique relationship has profound implications for microbial $\mathrm{C}$ loss during particle sinking and therefore for the efficiency of the oceanic BCP. We advocate that deciphering the prokaryotic species richnessfunction relationship is crucial to adequately represent climate relevant biogeochemical gradients. This is required for the future generation of biogeochemistry models based on the ecological traits of different prokaryotic communities (e.g., non- vs. fast-sinking) throughout the oceanic water column.

\section{Material and methods}

\section{Cruise details}

We collected samples during the DY032 cruise (RRS DISCOVERY, NERC, Southampton) from the $20^{\text {th }}$ of June to the $08^{\text {th }}$ of July 2015 at the PAP site (Porcupine Abyssal Plain, $49.0^{\circ} \mathrm{N}, 16.5^{\circ} \mathrm{W}$ ) in the North Atlantic. The cruise took place approximately two weeks after the main spring bloom [25]. The depth of the mixing layer $(28 \mathrm{~m})$ was determined by reference [25] following methods presented in reference [65].

\section{Sampling strategy}

Samples were collected at 28, 70, 128, and $500 \mathrm{~m}$ depth using both Niskin bottles and a MSC [18]. These depths correspond to MSCs sampling at $10 \mathrm{~m}, 50 \mathrm{~m}$, and $110 \mathrm{~m}$ below the base of the MLD, i.e., MLD $+10 \mathrm{~m}, \mathrm{MLD}+$ $50 \mathrm{~m}, \mathrm{MLD}+110 \mathrm{~m}$, respectively [25]. The MSC is designed to reduce turbulence during sampling in such manner that the particles harvested are not biologically, chemically, or morphologically altered. After sampling, MSCs were left $2 \mathrm{~h}$ on deck allowing particles to settle. Fast-sinking particles were thereby deposited at the bottom of the MSC and collected in a dedicated tray, slow-sinking particles in the 7-litre compartment above the plate and nonsinking fraction in the upper part of the MSC [18]. Three types of samples are shown in this study: seawater and suspended particles in either Niskin ${ }^{\circledR}$ bottles or the MSC's top part (both termed non-sinking), and fast-sinking particles from the MSC's plate (Fig. S1). The entire volume of the plate (around $243 \mathrm{~mL}$ ) was sampled with a pipette to collect all fast-sinking particles. As fast-sinking particles 
were concentrated during a $2 \mathrm{~h}$ period of settlement, measurements values required normalization to the entire volume of the MSC $(100 \mathrm{~L})$. In addition, we assumed that the fast-sinking fraction contained seawater, slow-sinking, suspended and primarily fast-sinking particles. We therefore use the formula shown in Fig. S1 to obtain values associated to fast-sinking particles only, quantitatively removing the contribution of other fractions. This formula is adapted from reference [18], who used it for the slow-sinking fraction (a fraction not considered in the present study). On occasion, the fast-sinking particle slurry collected in the plate was further diluted in sterile seawater (filtered and autoclaved) to ease handling. Then, dilution factors were also applied (Fig. S1). Various measurements were performed on the fractions described above. These are detailed below. We estimated the maximum temperature the $100 \mathrm{~L}$ of the MSC may reach after $2 \mathrm{~h}$ settling on deck to calorimetry and the heat transfer calculations. We used a specific heat capacity of water and the heat conductivity properties of the MSC walls $(1.5 \mathrm{~m}$ height, $0.3 \mathrm{~m}$ radius and $0.01 \mathrm{~m}$ thickness of plastic), for an initial temperature of $12^{\circ} \mathrm{C}$ (see Fig. S2), a temperature on deck of $18{ }^{\circ} \mathrm{C}$ and assuming steady state. After $2 \mathrm{~h}$, the temperature of the water collected will be $14.6^{\circ} \mathrm{C}$.

\section{Prokaryotic heterotrophic production measurements (PHP)}

Prokaryotic heterotrophic production (PHP) was measured, in triplicates, by incorporating L-[4,5-3H]-Leucine, ( ${ }^{3} \mathrm{H}-\mathrm{Leu}$, $108 \mathrm{Ci} \mathrm{mmol}^{-1}$ of specific activity, PerkinElmer ) to get a final saturation concentration of $20 \mathrm{nM}$ according to [66]. Samples collected at 28,70 , and $128 \mathrm{~m}$ were incubated for four hours. Samples collected at $500 \mathrm{~m}$ were incubated for 6 h. All samples were incubated at temperatures corresponding to that observed in situ. To convert pmol Leu $\mathrm{L}^{-1} \mathrm{~h}^{-1}$ into produced carbon biomass (equal to carbon loss), we chose a conversion factor of $1.55 \mathrm{~kg} \mathrm{C} \mathrm{pmol}^{-1}$ Leu incorporated and assumed an isotopic dilution equal to 1 according to [67].

\section{Total community growth rates}

We determined growth rates of the total prokaryotic community attached to sinking particles using cell-specific PHP rates (shown in Fig. 1). We assumed a conservative conversion factor of $12 \mathrm{fg} \mathrm{C}$ cell $^{-1}$ from [68]. Our calculation is explained by the following dimensional equation (1):

$$
\left(\text { ng C cell }{ }^{-1} h^{-1}\right) /\left(\text { fgC cell }{ }^{-1}\right)=h^{-1}
$$

This conversion yields prokaryotic growth rates expressed in $\mathrm{h}^{-1}$.

\section{Heterotrophic prokaryotic cells concentration}

Heterotrophic prokaryotic cells concentration from nonsinking and Niskin samples were counted using a flow cytometer "Flow cytometer analyzer FACSCalibur" (BD Biosciences). Ten ml of sample were collected, fixed with $100 \mu \mathrm{l}$ of $25 \%$ glutaraldehyde and stored at $-80^{\circ} \mathrm{C}$ for further analysis. We combined our cell concentration to that found by reference [17] to estimate the concentration of cells associated with fast-sinking particles. Taking cell concentration of the non-sinking pool at $28,70,128$, and $500 \mathrm{~m}$ depth and power law estimations (at the same depths) derived from their sinking pool values, we were able to obtain ratios between both fractions. Applying these ratios to cell concentration of our non-sinking pool, we provide an estimation of cell concentration associated with fast-sinking particles. Non-sinking samples ranged from $2.10 \pm 0.94 \times 106$ to $1.97 \pm 0.99 \times 105$ cells $\mathrm{ml}^{-1}$ from 28 to $500 \mathrm{~m}$, respectively. Briefly, fast-sinking particles would represent a concentration factor between 1768 and 397 at $28 \mathrm{~m}$ and between 836 and 377 at $500 \mathrm{~m}$. Thus, the fast-sinking pool from 28 to $500 \mathrm{~m}$ would account for $2.27 \pm 2.03 \times 109$ and $1.2 \pm 0.64 \times 108$ prokaryotic cells $\mathrm{ml}^{-1}$ of particle, respectively.

\section{S rRNA extraction, sequencing and metabarcoding library preparation}

For Niskin, MSC non-sinking and fast-sinking fractions, 1750,1750 , and $10 \mathrm{ml}$ were filtered onto $0.2 \mu \mathrm{m}$ membrane, respectively. Filters were treated with TE-Lysis buffer (20 $\mathrm{mM}$ Tris, $25 \mathrm{mM}$ EDTA, $1 \mu \mathrm{g} \mu \mathrm{l}^{-1}$ Lysozyme) followed by $10 \%$ SDS (sodium dodecylsulfate). Extractions were performed twice with an equal volume of phenol:chloroform: isoamyl alcohol pH 6 16S-rRNA. 16S-rRNA samples were then treated with TurboDNaseTM (Ambion", Thermo Fisher Scientific Corp.) and reverse transcribed into cDNA by RT-PCR using SuperScript IV Reverse Transcriptase with random primers (Life Technologies, Thermo Fisher Scientific Corp.). For ribosomal diversity analysis, the V4 region of the bacterial and archaeal $16 \mathrm{~S}$ cDNA product were amplified using universal primer sets [69], 515F-Y (5'-GTGYCAGCMGCCGCGGTAA-3') [70], and 806RB (5'-GGACTACNVGGGTWTCTAAT-3') [71] as well as $2.5 \mathrm{U} / 50 \mu \mathrm{L}$ TaKaRa PrimeSTAR ${ }^{\circ}$ GXL DNA polymerase (OZYME). The $16 \mathrm{~S}$ amplicons were sequenced via MiSeq Illumina (paired end $2 * 250$ ) platform GeT of Genotoul (https://get.genotoul.fr/en/). 16S-rRNA raw read sequences are deposited on Short Read Archive (accession number are ranged from SRR11997098 to SRR11997133 and the SRA accession is PRJNA638895). Blanks were systematically performed and checked on electrophoresis gels. No nucleic 
acid was amplified on any of our blanks suggesting no contamination during sample processing.

\section{Analysis of sequencing data}

Raw data was analyzed using DADA2, a model-based approach for correcting amplicon sequencing errors [72]. After inspection of quality read profiles, the $16 \mathrm{~S}$ rRNA paired-end reads were quality trimmed and only reads $>150$ bp were retained. The paired-end reads were then dereplicated, denoised (DADA2 error correction model), assembled, and chimeras were discarded (Table S3). The high-quality and denoising sequences obtained are amplicon sequence variants (ASVs). A post clustering curation [73] of ASVs into OTU was applied to minimize the effect of intraspecific heterogeneity of rDNA copy number in strains/species. The OTU clustering is based on a sequence identity threshold of 97\% and performed by DECIPHER package [74]. The taxonomic assignment of OTUs was performed using the SILVA_132 database [75] with $100 \%$ identity required for species rank. Finally, sub-sampling normalization, alpha and beta diversity were characterized by the Phyloseq, R package [76]. From a total of 1121933 sequences found in our 36 samples, 850234 sequences, i.e., $76 \%$ were retained after the pre-processing (quality control, merging and chimera removal, Table S3). In addition, rarefaction curves quickly plateaued after pre-processing (Fig. S5). This verifies a sufficient sequencing depth for our study (Table S3).

Our metabarcoding library has been generated from short $16 \mathrm{~S}$ amplicons (about $290 \mathrm{bp}$ ). The size of the $16 \mathrm{~S}$ amplicons does not allow accurate taxonomic assignment. Yet, such approach does not capture sufficient sequence variation to adequately discriminate closely related taxa [77]. As a result, we assigned only $31 \%$ of all OTUs at the genus level in all our samples combined. This low assigned taxonomic fraction can also result from uncharacterized marine microorganisms absent from $16 \mathrm{~S}$ databases. In comparison 54\% were assigned at the family level. For this reason, we did not assign further than the family level. However, we deepened the phylogenetic assignment only for the few genera that were most relevant (see Fig. 2).

\section{Statistical analysis}

Statistical analyses were performed with the $\mathrm{R}$ statistics software (https://www.r-project.org). The species richness (observed species richness (species number in a sample) and Chaol (the common species richness estimator)), the community diversity (Shannon index) and evenness (Simpson index) were all calculated using the alpha diversity function from the Phyloseq $R$ package [76]. Non-metric multidimensional scaling (NMDS) ordination plot (Fig. 1) of
Bray-Curtis community dissimilarities between samples was performed using the Phyloseq $\mathrm{R}$ package [76]. The resulting graphs were all constructed using ggplot $2 \mathrm{R}$ package [78]. Statistical tests are provided in Table S4 and diversity indices in Fig. S3 and Table S5. All error bars in figures correspond to standard deviations from triplicate measurements.

Acknowledgements We thank the crew and officers of the R.R.S. DISCOVERY (NERC) for their help during the DY032 cruise. We would like to thank Prof. Richard Lampitt (NOC Southampton) for supporting our work at the Porcupine Abyssal Plain. Dr. Anna Belcher (formerly NOC Southampton) is thanked for helping with deployments. This work was partly funded by Labex OT-Med (ANR-11LABEX-0061 www.otmed.fr) Investissements d'Avenir, French Government project of the ANR, through the AMidex ROBIN project (ANR-11-IDEX-0001-02 to F.A.C.L.M. and C.T.). Part of the equipment used in this work was funded by European Regional Development Fund (ERDF). The project associated to this publication has received funding from European ERDF Fund under project 116639417. We thank Dr. Mark Hopwood (GEOMAR, Kiel) for language editing and Prof. Maria Villa (Univ of Sevilla) for help with calculation. We warmly thanks the three reviewers for their constructive feedbacks on our work.

Author contributions C.T. and F.A.C.L.M. conceived this work; M.G., C.T., N.B., S.G., V.R. conducted fieldwork and laboratory analysis; C.M.J.B., M.G. and F.A. conducted the gene analysis work. H.P.G. advised on interpretations. C.M.J.B., F.A.C.L.M., C.T., and H.P.G. wrote the manuscript with all authors contributing to its revision.

\section{Compliance with ethical standards}

Conflict of interest The authors declare that they have no conflict of interest.

Publisher's note Springer Nature remains neutral with regard to jurisdictional claims in published maps and institutional affiliations.

Open Access This article is licensed under a Creative Commons Attribution 4.0 International License, which permits use, sharing, adaptation, distribution and reproduction in any medium or format, as long as you give appropriate credit to the original author(s) and the source, provide a link to the Creative Commons license, and indicate if changes were made. The images or other third party material in this article are included in the article's Creative Commons license, unless indicated otherwise in a credit line to the material. If material is not included in the article's Creative Commons license and your intended use is not permitted by statutory regulation or exceeds the permitted use, you will need to obtain permission directly from the copyright holder. To view a copy of this license, visit http://creativecommons. org/licenses/by/4.0/.

\section{References}

1. Eppley RW, Peterson BJ. Particulate organic matter flux and planktonic new production in the deep ocean. Nature. 1979;282: 677-80.

2. Boyd PW, Claustre H, Levy M, Siegel DA, Weber T. Multifaceted particle pumps drive carbon sequestration in the ocean. Nature. 2019;568:327-35. 
3. Le Moigne FAC Pathways of organic carbon downward transport by the oceanic biological carbon pump. Front Mar Sci. 2019; https://doi.org/10.3389/fmars.2019.00634 SMASH.

4. Kwon EY, Primeau F, Sarmiento JL. The impact of remineralization depth on the air-sea carbon balance. Nat Geosci. 2009; 2:630-5.

5. Koski M, Valencia B, Newstead R, Thiele C. The missing piece of the upper mesopelagic carbon budget? Biomass, vertical distribution and feeding of aggregate-associated copepods at the PAP site. Prog Oceanogr. 2020;181:102243.

6. Briggs N, Dall'Olmo G, Claustre H. Major role of particle fragmentation in regulating biological sequestration of $\mathrm{CO} 2$ by the oceans. Science (80-). 2020;367:791-3.

7. Cho BC, Azam F. Major role of bacteria in biogeochemical fluxes in the ocean's interior. Nature. 1988;332:441-3.

8. Azam F, Long RA Sea snow microcosms. Nature. 2001, 414

9. Giering SLC, Sanders R, Lampitt RS, Anderson TR, Tamburini C, Boutrif $\mathrm{M}$, et al. Reconciliation of the carbon budget in the ocean's twilight zone. Nature. 2014;507:480-3.

10. Burd AB, Hansell DA, Steinberg DK, Anderson TR, Arístegui J, Baltar F, et al. Assessing the apparent imbalance between geochemical and biochemical indicators of meso- and bathypelagic biological activity: What the @\$\#! is wrong with present calculations of carbon budgets? Deep Res Part II Top Stud Oceanogr. 2010;57:1557-71.

11. Collins JR, Edwards BR, Thamatrakoln K, Ossolinski JE, Ditullio GR, Bidle KD, et al. The multiple fates of sinking particles in the North Atlantic Ocean. Global Biogeochem Cycles. 2015;29:1471-94.

12. Mestre M, Ruiz-González C, Logares R, Duarte CM, Gasol JM, Sala MM. Sinking particles promote vertical connectivity in the ocean microbiome. Proc Natl Acad Sci. 2018;115:E6799_ E6807.

13. Planquette H, Sherrell RM. Sampling for particulate trace element determination using water sampling bottles: Methodology and comparison to in situ pumps. Limnol Oceanogr Methods. 2012;10:367-88.

14. Puigcorbé V, Ruiz-González C, Masqué P, Gasol JM. Sampling device-dependence of prokaryotic community structure on marine particles: higher diversity recovered by in situ pumps than by oceanographic bottles. Front Microbiol. 2020;11:1645.

15. Grossart H-P. Ecological consequences of bacterioplankton lifestyles: changes in concepts are needed. Environ Microbiol Rep. 2010;2:706-14.

16. Boeuf D, Edwards BR, Eppley JM, Hu SK, Poff KE, Romano AE, et al. Biological composition and microbial dynamics of sinking particulate organic matter at abyssal depths in the oligotrophic open ocean. Proc Natl Acad Sci USA. 2019;116:11824-32.

17. Turley C, Mackie P. Biogeochemical significance of attached and free-living bacteria and the flux of particles in the NE Atlantic Ocean. Mar Ecol Prog Ser. 1994;115:191-203.

18. Riley J, Sanders R, Marsay C, Le Moigne FAC, Achterberg E, Poulton A. The relative contribution of fast and slow sinking particles to ocean carbon export. Global Biogeochem Cycles. 2012;26:GB1026.

19. Duret MT, Lampitt RS, Lam P. Prokaryotic niche partitioning between suspended and sinking marine particles. Environ Microbiol Rep. 2019;11:386-400.

20. Schmidt ML, Biddanda BA, Weinke AD, Chiang E, Januska F, Props R, et al. Microhabitats are associated with diversity-productivity relationships in freshwater bacterial communities. FEMS Microbiol Ecol. 2020;96:fiaa029.

21. Guidi L, Chaffron S, Bittner L, Eveillard D, Larhlimi A, Roux S, et al. Plankton networks driving carbon export in the oligotrophic ocean. Nature. 2016;532:465-70.
22. Ibarbalz FM, Henry N, Brandão MC, Martini S, Busseni G, Byrne $\mathrm{H}$, et al. Global trends in marine plankton diversity across kingdoms of life. Cell. 2019;14:1084-97.

23. Martin A, Boyd P, Buesseler K, Cetinic I, Claustre H, Giering S, et al. The oceans' twilight zone must be studied now, before it is too late. Nature. 2020;580:26-8.

24. Sanders RJ, Henson SA, Koski M, De La Rocha C, Painter SC, Poulton AJ, et al. The biological carbon pump in the North Atlantic. Prog Oceanogr. 2014;129:200-18.

25. Belcher A, Iversen M, Giering S, Riou V, Henson SA, Berline L, et al. Depth-resolved particle-associated microbial respiration in the northeast Atlantic. Biogeosciences. 2016;13:4927-43.

26. Simon M, Grossart H, Schweitzer B, Ploug H. Microbial ecology of organic aggregates in aquatic ecosystems. Aquat Micro Ecol. 2002;28:175-211.

27. De Corte D, Sintes E, Yokokawa T, Lekunberri I, Herndl GJ. Large-scale distribution of microbial and viral populations in the South Atlantic Ocean. Environ Microbiol Rep. 2016;8:305-15.

28. Mende DR, Bryant JA, Aylward FO, Eppley JM, Nielsen T, Karl $\mathrm{DM}$, et al. Environmental drivers of a microbial genomic transition zone in the ocean's interior. Nat Microbiol. 2017;2:1367-73.

29. Ducklow H. Bacterial production and biomass in the oceans. Microbial Ecol Oceans. In: Kirchman DL, editor. Microbial Ecology of The Oceans. New York: John Wiley \& Sons; 2000. p. 85-120.

30. Krizova L, Maixnerova M, Sedo O, Nemec A. Acinetobacter albensis sp. Nov., isolated from natural soil and water ecosystems. Int J Syst Evol Microbiol. 2015;65:3905-12.

31. Tabor PS, Ohwada K, Colwell RR. Filterable marine bacteria found in the deep sea: Distribution, taxonomy, and response to starvation. Microb Ecol. 1981;7:67-83.

32. Milici M, Vital M, Tomasch J, Badewien TH, Giebel HA, Plumeier I, et al. Diversity and community composition of particle-associated and free-living bacteria in mesopelagic and bathypelagic Southern Ocean water masses: Evidence of dispersal limitation in the Bransfield Strait. Limnol Oceanogr. 2017;62:1080-95.

33. Pelve EA, Fontanez KM, DeLong EF. Bacterial succession on sinking particles in the ocean's interior. Front Microbiol. 2017; 8:2269.

34. Parkes RJ, Cragg B, Roussel E, Webster G, Weightman A, Sass H. A review of prokaryotic populations and processes in subseafloor sediments, including biosphere: geosphere interactions. Mar Geol. 2014;352:409-25.

35. Riou V, Para J, Garel M, Guigue C, Al Ali B, Santinelli C, et al. Biodegradation of Emiliania Huxleyi aggregates by natural prokaryotic communities under increasing hydrostatic pressure. Prog Oceanogr. 2017;63:271-81.

36. Tamburini C, Goutx M, Guigue C, Garel M, Lefevre D, Charriere $\mathrm{B}$, et al. Effects of hydrostatic pressure on microbial alteration of sinking fecal pellets. Deep Res II. 2009;56:1533-46.

37. Frank AH, Garcia JAL, Herndl GJ, Reinthaler T. Connectivity between surface and deep waters determines prokaryotic diversity in the North Atlantic Deep Water. Environ Microbiol. 2016;18:2052-63.

38. De Corte D, Sintes E, Winter C, Yokokawa T, Reinthaler T, Herndl GJ. Links between viral and prokaryotic communities throughout the water column in the (sub)tropical Atlantic Ocean. ISME J. 2010;4:1431-42.

39. Grossart HP, Gust G. Hydrostatic pressure affects physiology and community structure of marine bacteria during settling to $4000 \mathrm{~m}$ : an experimental approach. Mar Ecol Prog Ser. 2009;390:97-104.

40. Kiørboe T, Jackson GA. Marine snow, organic solute plumes, and optimal chemosensory behavior of bacteria. Limnol Oceanogr. 2001;46:1309-18.

41. Azam F, Malfatti F. Microbial structuring of marine ecosystems. Nat Rev Microbiol. 2007;5:782-91. 
42. Carlson CA, Giovannoni SJ, Hansell DA, Goldberg SJ, Parsons R, Vergin K. Interactions among dissolved organic carbon, microbial processes, and community structure in the mesopelagic zone of the northwestern Sargasso Sea. Limnol Oceanogr. 2004;49:1073-83.

43. Preston CM, Durkin CA, Yamahara KM. DNA metabarcoding reveals organisms contributing to particulate matter flux to abyssal depths in the North East Pacific ocean. Deep Sea Res Part II Top Stud Oceanogr. 2020;173:104708.

44. Baumann P. Isolation of acinetobacter from soil and water. $\mathrm{J}$ Bacteriol. 1968;96:32-42.

45. Dennis JJ, Sokol PA. Electrotransformation of pseudomonas. Methods Mol Biol. 1995;47:125-33.

46. Stover CK, Pham XQ, Erwin AL, Mizoguchi SD, Warrener P, Hickey MJ, et al. Complete genome sequence of Pseudomonas aeruginosa PAO1, an opportunistic pathogen. Nature. 2000;406: 959-64.

47. Kaneko H, Takami H, Inoue A, Horikoshi K. Effects of hydrostatic pressure and temperature on growth and lipid composition of the inner membrane of barotolerant Pseudomonas sp. BT1 isolated from the deep-sea. Biosci Biotechnol Biochem. 2000;64:72-9.

48. Barbe V, Vallenet D, Fonknechten N, Kreimeyer A, Oztas S, Labarre $\mathrm{L}$, et al. Unique features revealed by the genome sequence of Acinetobacter sp. ADP1, a versatile and naturally transformation competent bacterium. Nucleic Acids Res. 2004;32:5766-79.

49. Mann EE, Wozniak DJ. Pseudomonas biofilm matrix composition and niche biology. FEMS Microbiol Rev. 2012;36:893-916.

50. Doughari HJ, Ndakidemi PA, Human IS, Benade S. The ecology, biology and pathogenesis of acinetobacter spp.: an overview. Microbes Environ. 2011;26:101-12.

51. Swan BK, Martinez-Garcia M, Preston CM, Sczyrba A, Woyke T, Lamy D, et al. Potential for chemolithoautotrophy among ubiquitous bacteria lineages in the dark ocean. Science. (80-). 2011; 333:1296-300.

52. Thiele S, Fuchs BM, Amann R, Iversen MH. Colonization in the photic zone and subsequent changes during sinking determine bacterial community composition in marine snow. Appl Environ Microbiol. 2015;81:1463-71.

53. Irigoien $\mathrm{X}$, Hulsman $\mathrm{J}$, Harris RP. Global biodiversity patterns of marine phytoplankton and zooplankton. Nature. 2004;429:863-7.

54. Vallina SM, Follows MJ, Dutkiewicz S, Montoya JM, Cermeno P, Loreau M. Global relationship between phytoplankton diversity and productivity in the ocean. Nat Commun. 2014;5:4299.

55. Del Giorgio PA, Duarte CM. Respiration in the open ocean. Nature. 2002;420:379-84.

56. Waide RB, Willig MR, Steiner CF, Mittelbach G, Gough L, Dodson SI, et al. The relationship between productivity and species richness. Annu Rev Ecol Syst. 1999;30:257-300.

57. Weisser WW, Roscher C, Meyer ST, Ebeling A, Luo G, Allan E, et al. Biodiversity effects on ecosystem functioning in a 15 -year grassland experiment: patterns, mechanisms, and open questions. Basic Appl Ecol. 2017;23:1-73.

58. Wakeham SG, Lee C, Peterson ML, Liu ZF, Szlosek J, Putnam IF, et al. Organic biomarkers in the twilight zone-Time series and settling velocity sediment traps during MedFlux. Deep Res Part IiTopical Stud Oceanogr. 2009;56:1437-53.

59. Wilson B, Müller O, Nordmann E-L, Seuthe L, Bratbak G, Øvreås L. Changes in marine prokaryote composition with season and depth over an arctic polar year. Front Mar Sci. 2017;4:1-17.

60. Ghiglione JF, Galand PE, Pommier T, Pedrós-Alió C, Maas EW, Bakker K, et al. Pole-to-pole biogeography of surface and deep marine bacterial communities. Proc Natl Acad Sci USA. 2012; 109:17633-8.
61. Follows MJ, Dutkiewicz S, Grant S, Chisholm SW. Emergent biogeography of microbial communities in a model ocean. Science (80-). 2007;315:1843-6.

62. Aumont O, Ethe C, Tagliabue A, Bopp L, Gehlen M. PISCES-v2: an ocean biogeochemical model for carbon and ecosystem studies. Geosci Model Dev. 2015;8:2413-65.

63. Ward BA, Follows MJ. Marine mixotrophy increases trophic transfer efficiency, mean organism size, and vertical carbon flux. Proc Natl Acad Sci USA. 2016;113:2958-63.

64. Coles VJ, Stukel MR, Brooks MT, Burd A, Crump BC, Moran MA, et al. Ocean biogeochemistry modeled with emergent traitbased genomics. Science (80-). 2017;358:1149-54.

65. Monterey, GI and Levitus, S: Seasonal Variability of Mixed Layer Depth for the World Ocean, US Gov. Printing Office, Washington, DC, 87 pp., 1997.

66. Kirchman D, K'nees E, Hodson R. Leucine incorporation and its potential as a measure of protein synthesis by bacteria in natural aquatic systems. Appl Environ Microbiol. 1985;49:599-607.

67. Simon M, Azam F. Protein content and protein synthesis rates of planktonic marine bacteria. Mar Ecol Prog Ser. 1989;51:201-13.

68. Fukuda R, Ogawa H, Nagata T, Koike I. Direct determination of carbon and nitrogen contents of natural bacterial assemblages in marine environments. Appl Environ Microbiol. 1998;64:3352-8.

69. Caporaso JG, Lauber CL, Walters WA, Berg-Lyons D, Huntley J, Fierer N, et al. Ultra-high-throughput microbial community analysis on the Illumina HiSeq and MiSeq platforms. ISME J. 2012; 6:1621-4.

70. Parada AE, Needham DM, Fuhrman JA. Every base matters: Assessing small subunit rRNA primers for marine microbiomes with mock communities, time series and global field samples. Environ Microbiol. 2016;18:1403-14.

71. Apprill A, Mcnally S, Parsons R, Weber L Minor revision to V4 region SSU rRNA 806R gene primer greatly increases detection of SAR11 bacterioplankton. Aquat Microb Ecol. 2015.

72. Callahan BJ, McMurdie PJ, Rosen MJ, Han AW, Johnson AJA, Holmes SP. DADA2: High-resolution sample inference from Illumina amplicon data. Nat Methods. 2016;13:581-3.

73. Kamenova S A flexible pipeline combining clustering and correction tools for prokaryotic and eukaryotic metabarcoding. Peer Community Ecol. 2020. https://doi.org/10.24072/pci. ecology.100043.

74. Wright ES. Using DECIPHER v2.0 to analyze big biological sequence data in R. R J. 2016;8:352-9.

75. Quast C, Pruesse E, Yilmaz P, Gerken J, Schweer T, Yarza P, et al. The SILVA ribosomal RNA gene database project: improved data processing and web-based tools. Nucleic Acids Res. 2012;41: D590-D596.

76. Mcmurdie PJ, Holmes S. phyloseq: An R package for reproducible interactive analysis and graphics of microbiome census data. PLoS ONE. 2013;8:e61217.

77. Johnson JS, Spakowicz DJ, Hong BY, Petersen LM, Demkowicz $\mathrm{P}$, Chen L, et al. Evaluation of 16S rRNA gene sequencing for species and strain-level microbiome analysis. Nat Commun. 2019;10:5029.

78. Wickham H ggplot2, 2nd Editio. ggplot2. New York, NY: Springer New York; 2009.

79. Xu Z, Wang M, Wu W, Li Y, Liu Q, Han Y, et al. Vertical Distribution of Microbial Eukaryotes $>$ From Surface to the Hadal Zone of the Mariana Trench. Front Microbiol. 2018;9:1-13.

80. Jing H, Xia X, Suzuki K, Liu H. Vertical profiles of bacteria in the tropical and subarctic oceans revealed by pyrosequencing. PLoS One. 2013;8:e79423.

81. Walsh EA, Kirkpatrick JB, Rutherford SD, Smith DC, Sogin M, D'Hondt S. Bacterial diversity and community composition from seasurface to subseafloor. ISME J. 2016;10:979-89. 
82. Yamada N, Fukuda H, Ogawa H, Saito H, Suzumura M. Heterotrophic bacterial production and extracellular enzymatic activity in sinking particulate matter in the western North Pacific Ocean. Front Microbiol. 2012;3:379.

83. Jiang $\mathrm{X}$, Jiao $\mathrm{N}$. Vertical distribution of bacterial communities in the indian ocean as revealed by analyses of $16 \mathrm{~S}$ rRNA and nasA Genes. Indian J Microbiol. 2016;56:309-17.
84. Goosen NK, Van Rijswijk P, De Bie M, Peene J, Kromkamp J. Bacterioplankton abundance and production and nanozooplankton abundance in Kenyan coastal waters (western Indian Ocean). Deep Res Part II Top Stud Oceanogr. 1997;39:1085-95.

85. Carlson CA, Ducklow HW, Hansell DA, Smith WO. Organic carbon partitioning during spring phytoplankton blooms in the Ross Sea polynya and the Sargasso Sea. Limnol Oceanogr. 1998;43:375-86. 